This item was submitted to Loughborough's Research Repository by the author.

Items in Figshare are protected by copyright, with all rights reserved, unless otherwise indicated.

\title{
A-posteriori error estimation in axisymmetric geotechnical analyses
}

PLEASE CITE THE PUBLISHED VERSION

PUBLISHER

(C) Elsevier

VERSION

AM (Accepted Manuscript)

LICENCE

CC BY-NC-ND 4.0

\section{REPOSITORY RECORD}

El-Hamalawi, Ashraf, and M.D. Bolton. 2019. "A-posteriori Error Estimation in Axisymmetric Geotechnical Analyses”. figshare. https://hdl.handle.net/2134/5160. 
This item was submitted to Loughborough's Institutional Repository (https://dspace.lboro.ac.uk/) by the author and is made available under the following Creative Commons Licence conditions.

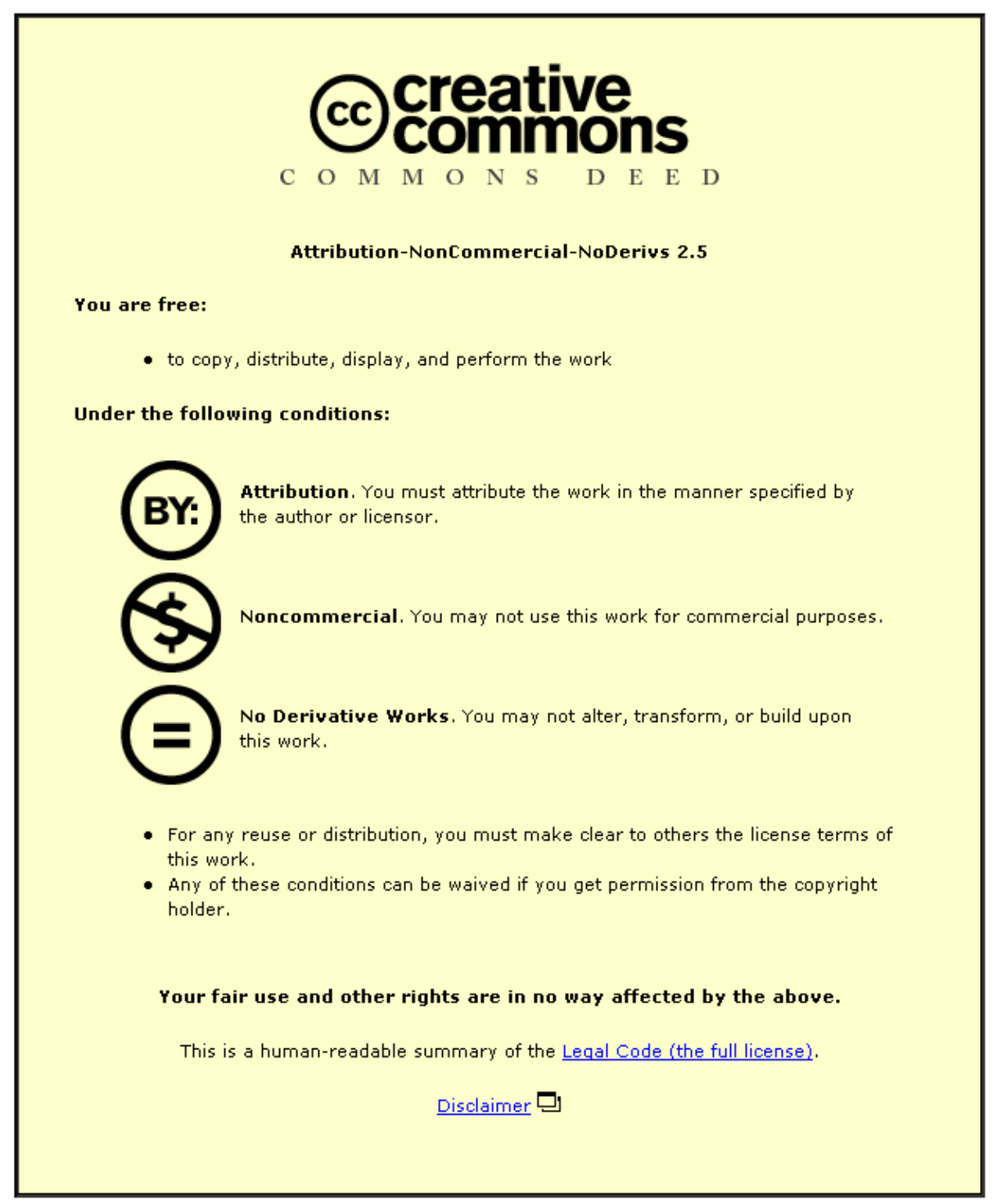

For the full text of this licence, please go to: http://creativecommons.org/licenses/by-nc-nd/2.5/ 


\section{a-posteriori error estimation in axisymmetric geotechnical analyses}

\section{A. EL-HAMALAWI ${ }^{1}$ AND M.D. BOLTON ${ }^{2}$}

\section{Abstract}

In this paper, an a-posteriori error estimator suitable for use in axisymmetric geotechnical analyses has been developed. The consolidation superconvergent patch recovery with equilibrium and boundaries (CSPREB) method, developed for plane-strain coupledconsolidation problems, is extended to axisymmetric analyses. The use of pore pressures in the error estimator was found to improve results when predicting consolidation. Collapse loads under undrained soil conditions are known to be over-predicted due to "locking", especially in axial symmetry where there are further displacement constraints. The proposed solution technique reduced locking slightly, but could not eliminate it, as it is inherent in the displacement formulation for lower order elements.

Keywords : error estimation, axisymmetric geotechnical finite element analysis, adaptive mesh refinement.

\section{Introduction}

For the majority of applications in geotechnical engineering, the finite element analysis of soil behaviour requires a lot of effort and time. Subjective assumptions can be made based on experience regarding the relative sizes of elements in a mesh, but in most real cases where time-dependency and multi-layered soils are involved, prior knowledge is lacking. Other situations occur where at one stage of the analysis, certain areas require refinement, while at a later stage, de-refinement is needed. Adaptive mesh refinement (AMR) is therefore a suitable environment in which to model such problems, where no assumptions of the anticipated failure mechanisms and behaviour of soil have to be made in advance.

\footnotetext{
${ }^{1}$ Civil \& Building Engineering Department, Loughborough University, Loughborough LE11 3AN, U.K. Corresponding Author.

${ }^{2}$ Cambridge University Engineering Department, Trumpington Street, Cambridge CB2 1PZ, U.K.
} 
Adaptive mesh refinement has been used in fields other than geomechanics. In geotechnical engineering, Zienkiewicz et al. [1] managed to capture both ideal and softening plastic behaviour of the soil for two undrained problems using adaptive remeshing. Hicks [2] analysed an undrained biaxial test, using adaptive mesh refinement with an error estimator based on strains. All these analyses however have been either short-term (undrained) or longterm (drained), where the intermediate stages of consolidation have not been taken into consideration. A wealth of literature exists on structural criteria, but no pore pressures included, which can be used for drained and undrained analyses. However, minimal attention has been focused on time-dependent geotechnical problems, which was the main reason behind the lack of use of AMR in consolidation analyses. El-Hamalawi and Bolton [3], [4] introduced the CSPREB method, where an error estimator incorporating pore pressures was developed for consolidation-based plane-strain problems. In this paper, the CSPREB method is extended to axisymmetric problems. The full formulation is described, followed by numerical examples to demonstrate the use and effectiveness of this criterion.

The non-linear time-dependent problem is analysed and the error criterion is checked at either every increment, or every group of increments as defined by the user. The mesh is then adapted if required. The analysis is either continued using the smoothed parameters based on the new error criterion, in addition to the updated constitutive D matrix, or the problem is re-analysed based on the newly adapted mesh. If the re-analysis option is chosen by the user, the analysis starts from the last point at which the mesh was previously adapted.

\section{Theory}

\subsection{Governing equations}

Consider the two-dimensional equilibrium and continuity equations (1) and (2) respectively, over a domain $\Omega$ with boundary $\Gamma$. For axisymmetric problems, cylindrical instead of rectangular co-ordinates are used, where the $x, y$ and $z$ axes are equivalent to the $r$, 
$z$ and $\theta$ axes respectively. The differential operator $\left[\mathrm{L}_{\mathrm{eq}}\right]$ is thus defined by equation (3a), while the stress vector $\{\sigma\}$, body forces $\{\omega\}$, and pore pressures $\left\{\sigma_{\mathrm{pp}}\right\}$, are defined by equation (3b). $k_{r}$ and $k_{z}$ are the permeabilities in the $r$ and $z$ directions respectively, $\gamma_{w}$ is the unit weight of water and $\varepsilon_{\mathrm{v}}$ is the volumetric strain. The boundary $\Gamma_{\sigma}$ is subject to the natural boundary conditions $\{\mathrm{n}\} \cdot\{\sigma\}=\left\{\sigma_{\mathrm{b}}\right\}$, and the essential displacement conditions $\mathrm{u}=\left\{\mathrm{u}_{\mathrm{b}}\right\}$ act on the boundary $\Gamma_{\mathrm{u}}$, where $\{\mathrm{n}\}$ is the outward unit normal vector. The excess pore pressure $\sigma_{\mathrm{pp}}=\left\{\sigma_{\mathrm{ppb}}\right\}$, acts on the $\Gamma_{\mathrm{pp}}$ boundary segment at time t.

$$
\begin{gathered}
\mathrm{L}_{\mathrm{eq}}{ }^{\mathrm{T}} \sigma+\omega=0 \\
\gamma_{\mathrm{w}} \frac{\partial^{2} \sigma_{p p}}{\partial \mathrm{r}^{2}}+\frac{\mathrm{k}_{\mathrm{z}}}{\gamma_{\mathrm{w}}} \frac{\partial^{2} \sigma_{p p}}{\partial \mathrm{z}^{2}}+\frac{\partial \varepsilon_{\mathrm{v}}}{\partial \mathrm{t}}=0 \\
\left.\left.\sigma=\left\{\begin{array}{cc}
\frac{\partial}{\partial \mathrm{r}}+\frac{1}{\mathrm{r}} & 0 \\
0 & \frac{\partial}{\partial \mathrm{z}} \\
\sigma_{\mathrm{z}} \\
\sigma_{\theta} \\
\sigma_{\mathrm{rz}}
\end{array}\right\}, \omega=\left\{\begin{array}{cc}
\omega_{\mathrm{r}} \\
\omega_{\mathrm{z}}
\end{array}\right\} \text { and } \sigma_{\mathrm{pp}}=\left\{\begin{array}{c}
\frac{1}{\mathrm{r}} \\
\frac{\partial}{\partial \mathrm{z}}
\end{array}\right] \begin{array}{c}
\frac{\partial}{\partial \mathrm{r}}+\frac{1}{\mathrm{r}}
\end{array}\right] \begin{array}{c}
\sigma_{\mathrm{pp}} \\
\sigma_{\mathrm{pp}} \\
0
\end{array}\right\}
\end{gathered}
$$

The constitutive relation used is Hooke's law, represented in matrix form by $\{\sigma\}=[D]\{\varepsilon\}$, where [D] is the constitutive matrix and $\{\varepsilon\}$ the strain (equation (4)). For elastoplastic materials, the constitutive relation still holds, but with [D] becoming the elasto-plastic matrix $\left[D_{e p}\right]$ defined by equation (5) rather than the elastic $\left[D_{e}\right]$. Compressive stresses are assumed positive in the derivations that follow. 


$$
\begin{aligned}
& \mathrm{D}=\left[\begin{array}{llll}
\mathrm{D}_{11} & \mathrm{D}_{12} & \mathrm{D}_{13} & \mathrm{D}_{14} \\
\mathrm{D}_{21} & \mathrm{D}_{22} & \mathrm{D}_{23} & \mathrm{D}_{24} \\
\mathrm{D}_{31} & \mathrm{D}_{32} & \mathrm{D}_{33} & \mathrm{D}_{34} \\
\mathrm{D}_{41} & \mathrm{D}_{42} & \mathrm{D}_{43} & \mathrm{D}_{44}
\end{array}\right], \varepsilon=\mathrm{L}_{\varepsilon} \mathrm{u}=\left\{\begin{array}{c}
\varepsilon_{\mathrm{r}} \\
\varepsilon_{\mathrm{z}} \\
\varepsilon_{\theta} \\
\gamma_{\mathrm{rz}}
\end{array}\right\}, \mathrm{L}_{\varepsilon}=-\left[\begin{array}{cc}
\frac{\partial}{\partial \mathrm{r}} & 0 \\
0 & \frac{\partial}{\partial \mathrm{z}} \\
\frac{1}{\mathrm{r}} & 0 \\
\frac{\partial}{\partial \mathrm{z}} & \frac{\partial}{\partial \mathrm{r}}
\end{array}\right] \\
& \mathrm{D}_{\mathrm{ep}}=\left[[\mathrm{I}]-\frac{\left[\mathrm{D}_{\mathrm{e}}\right]\left\{\frac{\partial \mathrm{g}}{\partial \sigma}\right\}\left\{\frac{\partial \mathrm{f}}{\partial \sigma}\right\}^{\mathrm{T}}}{\left\{\frac{\partial \mathrm{f}}{\partial \sigma}\right\}^{\mathrm{T}}\left[\mathrm{D}_{\mathrm{e}}\right]\left\{\frac{\partial \mathrm{g}}{\partial \sigma}\right\}-\left\{\frac{\partial \mathrm{f}}{\partial \varepsilon^{\mathrm{p}}}\right\}^{\mathrm{T}}\left\{\frac{\partial \mathrm{g}}{\partial \sigma}\right\}}\right]\left[\mathrm{D}_{\mathrm{e}}\right]
\end{aligned}
$$

Biot [5] developed the theory of coupled consolidation by coupling both equations (1) and (2). The finite element matrix format is derived by applying Galerkin’s weighted residual method to the equilibrium and continuity equations in turn. The first equation is obtained by starting with the equilibrium equation. The equivalent weak form is shown in equation (6).

$$
\int_{\Omega} \varepsilon^{\mathrm{T}} \sigma \mathrm{d} \Omega=\int_{\Omega} \mathrm{u}^{\mathrm{T}} \omega \mathrm{d} \Omega+\int_{\Gamma} \mathrm{u}^{\mathrm{T}} \sigma_{\mathrm{b}} \mathrm{d} \Gamma
$$

The total stress vector $\{\sigma\}$ is equal to the sum of the effective stress $\left\{\sigma^{\prime}\right\}$ and pore water pressures vector $\left\{\sigma_{\mathrm{pp}}\right\}$. This is substituted into equation (6), resulting in equation (7).

$$
\int_{\Omega} \varepsilon^{\mathrm{T}} \sigma^{\prime} \mathrm{d} \Omega+\int_{\Omega} \varepsilon^{\mathrm{T}} \sigma_{\mathrm{pp}} \mathrm{d} \Omega=\int_{\Omega} \mathrm{u}^{\mathrm{T}} \omega \mathrm{d} \Omega+\int_{\Gamma} \mathrm{u}^{\mathrm{T}} \sigma_{\mathrm{b}} \mathrm{d} \Gamma
$$

The displacements $\{u\}$ are approximated with the product of the nodal displacements $\{\bar{u}\}$ and shape functions $\left[N_{u}\right]$, where the strain $\{\varepsilon\}=\left[L_{\varepsilon}\right]\{u\}=\left[L_{\varepsilon}\right]\left[N_{u}\right]\{\bar{u}\}=[B]\{\bar{u}\}$. The effective stress vector $\left\{\sigma^{\prime}\right\}$ becomes equal to $[\mathrm{D}]\{\varepsilon\}=[\mathrm{D}][\mathrm{B}]\{\overline{\mathrm{u}}\}$. The pore pressures $\sigma_{\mathrm{pp}}$ are also approximated using $\left\{\sigma_{p p}\right\}=\left[N_{p p}\right]\left\{\bar{\sigma}_{p p}\right\}$, where $\left\{\bar{\sigma}_{p p}\right\}$ are the nodal pore pressures and $\left[\mathrm{N}_{\mathrm{pp}}\right]$ are the pore pressure shape functions. Composite displacement-pore pressure elements based on Sandhu and Wilson [6] are used, where the pore pressure variation is one order less than 
the displacement. Substituting these into equation (7) results in the first equation of the coupled consolidation matrix formulation shown in equation (8).

$$
\left(\int_{\Omega} \mathrm{B}^{\mathrm{T}} \mathrm{DB} \mathrm{d} \Omega\right) \overline{\mathrm{u}}+\left(\int_{\Omega} \mathrm{B}^{\mathrm{T}} \mathrm{N}_{\mathrm{pp}} \mathrm{d} \Omega\right) \bar{\sigma}_{\mathrm{pp}}=\int_{\Omega} \mathrm{N}_{\mathrm{u}}^{\mathrm{T}} \omega \mathrm{d} \Omega+\int_{\Gamma} \mathrm{N}_{\mathrm{u}}^{\mathrm{T}} \sigma_{\mathrm{b}} \mathrm{d} \Gamma
$$

Using the Galerkin weighted residual method, the product of equation (2) and an arbitrary function in the form of $\mathrm{N}_{\mathrm{pp}}$ is integrated by parts, resulting in equation (9), where $\left\{v_{n}\right\}$ is the seepage velocity normal to the boundary. Equation (10) shows the weak form of equation (2) after some mathematical simplification.

$$
\begin{gathered}
-\int_{\Omega}\left(\frac{\mathrm{k}_{\mathrm{r}}}{\gamma_{\mathrm{w}}} \frac{\partial \mathrm{N}_{\mathrm{pp}}}{\partial \mathrm{r}} \frac{\partial \sigma_{\mathrm{pp}}}{\partial \mathrm{r}}+\frac{\mathrm{k}_{\mathrm{z}}}{\gamma_{\mathrm{w}}} \frac{\partial \mathrm{N}_{\mathrm{pp}}}{\partial \mathrm{z}} \frac{\partial \sigma_{\mathrm{pp}}}{\partial \mathrm{z}}\right) \mathrm{d} \Omega-\int \mathrm{N}_{\mathrm{pp}}^{\mathrm{T}} \mathrm{v}_{\mathrm{n}} \mathrm{d} \Gamma_{\mathrm{pp}}+\int \mathrm{N}_{\mathrm{pp}}^{\mathrm{T}} \frac{\partial \varepsilon_{\mathrm{v}}}{\partial \mathrm{t}} \mathrm{d} \Omega=0 \\
\mathrm{~L}_{\mathrm{pp}}^{\mathrm{T}} \frac{\mathrm{d} \overline{\mathrm{u}}}{\mathrm{dt}}-\Phi \bar{\sigma}_{\mathrm{pp}}=\int_{\Gamma_{\mathrm{pp}}} \mathrm{N}_{\mathrm{pp}}^{\mathrm{T}} \mathrm{v}_{\mathrm{n}} \mathrm{d} \Gamma_{\mathrm{pp}}
\end{gathered}
$$

where $\mathrm{L}_{\mathrm{pp}}=\int_{\Omega} \mathrm{B}^{\mathrm{T}} \mathrm{N}_{\mathrm{pp}} \mathrm{d} \Omega, \Phi=\int_{\Omega} \frac{\mathrm{E}^{\mathrm{T}} \mathrm{kE}}{\gamma_{\mathrm{w}}} \mathrm{d} \Omega, \mathrm{E}=\left\{\begin{array}{c}\frac{\partial \mathrm{N}_{\mathrm{pp}}}{\partial \mathrm{r}} \\ \frac{\partial \mathrm{N}_{\mathrm{pp}}}{\partial \mathrm{z}}\end{array}\right\}$ and $\mathrm{k}=\left[\begin{array}{cc}\mathrm{k}_{\mathrm{r}} & 0 \\ 0 & \mathrm{k}_{\mathrm{z}}\end{array}\right]$

To simplify the time differential, equation (10a) is integrated with respect to time from time $\mathrm{t}$ to time $\mathrm{t}+\Delta \mathrm{t}$ using equation (11). Following Britto and Gunn [7] and based on Booker and Small [8], $\theta=1$ is assumed in order for the integration scheme to remain unconditionally stable.

$$
\begin{gathered}
\int_{t}^{t+\Delta t} f . d t \cong\left((1-\theta) f_{1}+\theta f_{2}\right) \Delta t, \theta=1 \Rightarrow \int_{t}^{t+\Delta t} f . d t \cong f_{2} \Delta t=\left(f_{t+\Delta t}-f_{t}\right) \Delta t \\
L_{p p}^{T} \Delta \bar{u}-\Phi \Delta \mathrm{t} \Delta \bar{\sigma}_{p p}=\Phi \Delta \mathrm{t} \Delta \bar{\sigma}_{p p 1}+\int_{\Gamma_{p p}} N_{p p}^{T} \mathrm{v}_{n 2} \Delta \mathrm{t} d \Gamma_{p p}
\end{gathered}
$$

This results in the second equation of the coupled consolidation matrix form shown in equation (12) in incremental form. Upon coupling with the incremental weak form of the equilibrium equations (8) and writing in matrix format, the final finite element coupled 
consolidation equations are reduced to

$$
\begin{gathered}
{\left[\begin{array}{cc}
\mathrm{K} & \mathrm{L}_{\mathrm{pp}} \\
\mathrm{L}_{\mathrm{pp}}^{\mathrm{T}} & -\Phi \Delta \mathrm{t}
\end{array}\right]\left\{\begin{array}{c}
\Delta \overline{\mathrm{u}} \\
\Delta \bar{\sigma}_{\mathrm{pp}}
\end{array}\right\}=\left\{\begin{array}{c}
\Delta \mathrm{r}_{1} \\
\Delta \mathrm{r}_{2}
\end{array}\right\}} \\
\mathrm{K}=\int_{\Omega} \mathrm{B}^{\mathrm{T}} \mathrm{DBd} \Omega, \Delta \mathrm{r}_{1}=\int_{\Omega} \mathrm{N}_{\mathrm{u}}^{\mathrm{T}} \omega \mathrm{d} \Omega+\int_{\Gamma_{\sigma}} \mathrm{N}_{\mathrm{u}}^{\mathrm{T}} \sigma_{\mathrm{b}} \mathrm{d} \Gamma_{\sigma} \text { and } \Delta \mathrm{r}_{2}=\Phi \Delta \mathrm{t} \Delta \bar{\sigma}_{\mathrm{pp} 1}+\int_{\Gamma_{\mathrm{pp}}} \mathrm{N}_{\mathrm{pp}}^{\mathrm{T}} \mathrm{v}_{\mathrm{n} 2} \Delta \mathrm{td} \Gamma_{\mathrm{pp}}
\end{gathered}
$$

The above equations are solved for the incremental displacements $\Delta \overline{\mathrm{u}}$ and pore pressures $\Delta \bar{\sigma}_{\mathrm{pp}}$, and marched forward in time to find a solution at time $\mathrm{t}+\Delta \mathrm{t}$ based on the solution at time t.

\subsection{Axisymmetric version of the CSPREB method}

Several error estimation methods and smoothing criteria exist in the literature, such as the Zienkiewicz and Zhu $\mathrm{Z}^{2}$ stress smoothing method [9] and superconvergent patch recovery method (SPR) [10], or the SPRE [11] and SPREB [12] methods by Wiberg and AbdulWahab, to name a few. A more detailed review of the criteria currently available is present elsewhere (e.g. [3], [4]). These methods have been shown to be suitable for structural problems, or for geotechnical problems where either pore pressures are non-existent, or are a function of the volumetric strain as in geotechnical undrained non-consolidation problems. However, the introduction of time-dependent changing pore pressures as extra unknown primary variables during the finite element analysis necessitates some extra parameters. The authors [4] have previously described the basis of the consolidation superconvergent patch recovery method incorporating equilibrium and boundary conditions (CSPREB) for plane strain problems. It involves fitting a least squares polynomial of one order higher than the shape functions for the displacements, and another for pore pressures at their optimal points in a patch of elements in order to obtain improved values of the latter. Variables such as strains, stresses and elasto-plasticity parameters are then updated based on the improved smoothed values. The main difference between this method and other error estimation methods developed is the introduction of pore pressures as an important parameter during adaptive mesh refinement, 
whose significance appears when performing coupled consolidation analyses. In this section, a modified formulation, applicable to axisymmetric problems, is outlined.

Equation (2) is simplified by integrating with respect to time in order to eliminate the partial time derivative, resulting in :

$$
\frac{\Delta t}{\gamma_{\mathrm{w}}}\left[\Delta\left(\mathrm{k}_{\mathrm{r}} \frac{\partial^{2} \sigma_{\mathrm{pp}}}{\partial \mathrm{r}^{2}}+\mathrm{k}_{\mathrm{z}} \frac{\partial^{2} \sigma_{\mathrm{pp}}}{\partial \mathrm{z}^{2}}\right)\right]+\mathrm{m}^{\mathrm{T}} \varepsilon=0, \mathrm{~m}=\left\{\begin{array}{l}
1 \\
1 \\
1 \\
0
\end{array}\right\} \text { for 2D problems }
$$

where $\mathrm{m}^{\mathrm{T}} \varepsilon$ is the volumetric strain, and the $\Delta$ operator indicates an incremental approach. The sum of the squares of the various residuals are defined by the functional $S$ :

$$
\begin{aligned}
\mathrm{S}= & \frac{1}{2}\left[\sum_{\mathrm{IP}} \mathrm{w}_{1}^{2}\left(\sigma^{\prime^{*}}-\sigma^{\prime}\right)^{2}+\sum_{\text {unod }} \mathrm{w}_{2}^{2}\left(\mathrm{u}^{*}-\mathrm{u}\right)^{2}+\sum_{\mathrm{ppnod}} \mathrm{w}_{3}^{2}\left(\sigma_{\mathrm{PP}}^{*}-\sigma_{\mathrm{pP}}\right)^{2}+\sum_{\text {bnod }} \mathrm{w}_{4}^{2}\left(\mathrm{n} \cdot \sigma^{*}-\sigma_{\mathrm{b}}\right)^{2}\right. \\
& \left.+\sum_{\mathrm{IP}} \mathrm{w}_{5}^{2}\left(\mathrm{~L}_{\text {eq }}^{\mathrm{T}} \sigma^{*}+\omega\right)^{2}+\sum_{\mathrm{IP}} \mathrm{w}_{6}^{2}\left(\frac{\Delta \mathrm{t}}{\gamma_{\mathrm{w}}}\left[\mathrm{k}_{\mathrm{r}} \frac{\partial^{2} \sigma_{\mathrm{PP}}^{*}}{\partial \mathrm{r}^{2}}+\mathrm{k}_{\mathrm{z}} \frac{\partial^{2} \sigma_{\mathrm{PP}}^{*}}{\partial \mathrm{z}^{2}}\right]+\mathrm{m}^{\mathrm{T}} \varepsilon^{*}\right)^{2}\right]
\end{aligned}
$$

The functional comprises several component residuals, and weightings have been added to each residual in order to control their effect on the overall functional. The first three components constitute the effective stress residual at the reduced integration points for quadrilaterals (or optimum points for triangles), the displacement residual at the displacement nodes, and the pore pressure residual at the pore pressure nodes respectively. For the weighting of the displacement components $\mathrm{w}_{2}$, vertex nodes have a weighting of three or four times that of element internal nodes, as suggested by Wiberg and AbdulWahab [11]. The weighting $w_{1}$ is taken as the inverse of the elastic modulus, while $w_{2}$ and $w_{3}$ are taken as equal to 2 for vertex nodes and 0.5 for non-vertex nodes. Boundary fixed displacement and pore pressure nodes are also given a much higher weighting. The finite element solution satisfies essential boundary conditions, hence a high weighting is used in order to ensure that the improved displacements and pore pressures at the respective nodes are as close as possible, if not, equal to the actual boundary values. The fourth residual comprises the boundary traction 
conditions at the boundary nodes. It has however been found from numerical experimentation [3] that this condition can be too rigid a condition to satisfy, as excessive element refinement occurs near the boundary, so $\mathrm{w}_{4}$ may be assumed to be equal to zero for most analyses.

Included in the functional is an equilibrium equation residual $w_{5}$, which tries to satisfy equilibrium locally in the element patches in a least squares sense. In general, the finite element method does not always satisfy the equilibrium equations locally, but does globally. This weighting acts as a penalty number, which can be thought of as the relative weight of the equilibrium residual with respect to the stress residual. It has been empirically found [3] that the weighting $w_{5}$ of 100 provides a good solution for most problems. The last term in the functional, weighted by $\mathrm{w}_{6}$, is the continuity equation, which similar to the equilibrium equation, the CSPREB method tries as much as possible to satisfy in a local sense, rather than just globally.

Polynomials of one order higher than $\mathrm{N}_{\mathrm{u}}$ and $\mathrm{N}_{\mathrm{pp}}$ are assumed for the displacements $\left\{\mathrm{u}^{*}\right\}=\left[\mathrm{P}_{\mathrm{a}}\right]\{\mathbf{a}\}$ and the pore pressures $\left\{\sigma_{\mathrm{pp}}^{*}\right\}=\left[\mathrm{P}_{\mathrm{b}}\right]\{\mathbf{b}\}$ in the patch respectively, as shown in equation (16). $\mathrm{P}_{\mathrm{a}}$ and $\mathrm{P}_{\mathrm{b}}$ are the co-ordinate term matrices and $\mathbf{a}$ and $\mathbf{b}$ are the unknown coefficient vectors. The smoothed effective stresses are substituted in the form $\left\{\sigma^{\prime *}\right\}=[\mathrm{D}]\left[\mathrm{L}_{\varepsilon}\right]\left\{\mathrm{u}^{*}\right\}=[\mathrm{D}]\left[\mathrm{L}_{\varepsilon}\right]\left[\mathrm{P}_{\mathrm{a}}\right]\{\mathbf{a}\}=[\mathrm{M}]\{\mathbf{a}\}$ where $[\mathrm{M}]=[\mathrm{D}]\left[\mathrm{L}_{\varepsilon}\right]\left[\mathrm{P}_{\mathrm{a}}\right],\left[\mathrm{L}_{\varepsilon}\right]$ is the strain operator and $\sigma^{*}={\sigma^{\prime}}^{*}+\sigma_{p p}^{*}$.

$$
\mathrm{u}=\left\{\begin{array}{c}
\mathrm{u}_{\mathrm{r}} \\
\mathrm{u}_{\mathrm{z}}
\end{array}\right\}=\mathrm{P}_{\mathrm{a}} \mathrm{a}=\left[\begin{array}{cc}
\mathrm{P}_{\mathrm{a}} & 0 \\
0 & \mathrm{P}_{\mathrm{a}}
\end{array}\right]\left\{\begin{array}{c}
\mathrm{a}_{\mathrm{r}} \\
\mathrm{a}_{\mathrm{z}}
\end{array}\right\}, \sigma_{\mathrm{pp}}=\left\{\begin{array}{c}
\sigma_{\mathrm{pp}} \\
\sigma_{\mathrm{pp}} \\
\sigma_{\mathrm{pp}} \\
0
\end{array}\right\}=\left\{\begin{array}{c}
\mathrm{P}_{\mathrm{b}} \mathbf{b} \\
\mathrm{P}_{\mathrm{b}} \mathbf{b} \\
\mathrm{P}_{\mathrm{b}} \mathbf{b} \\
0
\end{array}\right\}
$$

The functional $S$ thus becomes: 


$$
\begin{aligned}
\mathrm{S}= & \frac{1}{2}\left[\sum_{\mathrm{IP}} \mathrm{w}_{1}^{2}\left(\mathrm{Ma}-\sigma^{\prime}\right)^{2}+\sum_{\text {unod }} \mathrm{w}_{2}^{2}\left(\mathrm{P}_{\mathrm{a}} \mathbf{a}-\mathrm{u}\right)^{2}+\sum_{\text {ppnod }} \mathrm{w}_{3}^{2}\left(\mathrm{P}_{\mathrm{b}} \mathbf{b}-\sigma_{\mathrm{pp}}\right)^{2}+\sum_{\text {bnod }} \mathrm{w}_{4}^{2}\left(\mathrm{n}\left(\mathrm{Ma}+\mathrm{P}_{\mathrm{b}} \mathbf{b}\right)-\sigma_{\mathrm{b}}\right)^{2}\right. \\
& \left.+\sum_{\mathrm{IP}} \mathrm{w}_{5}^{2}\left(\mathrm{~L}_{\mathrm{eq}}^{\mathrm{T}}\left(\mathrm{Ma}+\mathrm{P}_{\mathrm{b}} \mathbf{b}\right)+\omega\right)^{2}+\sum_{\mathrm{IP}} \mathrm{w}_{6}^{2}\left(\frac{\Delta \mathrm{t}}{\gamma_{\mathrm{w}}}\left[\mathrm{k}_{\mathrm{r}} \frac{\partial^{2} \mathrm{P}_{\mathrm{b}} \mathbf{b}}{\partial \mathrm{r}^{2}}+\mathrm{k}_{\mathrm{z}} \frac{\partial^{2} \mathrm{P}_{\mathrm{b}} \mathbf{b}}{\partial \mathrm{z}^{2}}\right]+\mathrm{m}^{\mathrm{T}} \mathrm{L}_{\varepsilon} \mathrm{P}_{\mathrm{a}} \mathbf{a}\right)^{2}\right]
\end{aligned}
$$

Minimising $S$ with respect to the two unknown coefficient vectors a and $\mathbf{b}$ and collecting terms:

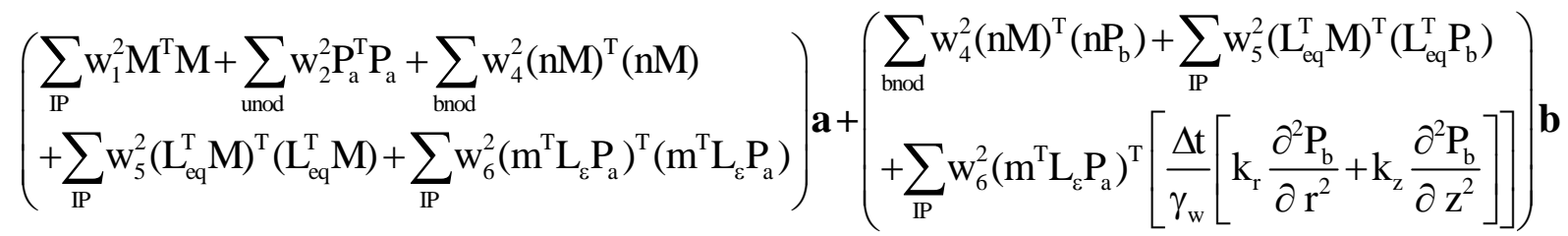

$$
\begin{aligned}
& =\left[\sum_{\mathbb{I P}} \mathrm{w}_{1}^{2} \mathrm{M}^{\mathrm{T}} \sigma^{\prime}+\sum_{\text {unod }} \mathrm{w}_{2}^{2} \mathrm{P}_{\mathrm{a}}^{\mathrm{T}} \mathrm{u}+\sum_{\text {bnod }} \mathrm{w}_{4}^{2}(\mathrm{nM})^{\mathrm{T}} \sigma_{\mathrm{b}}+\sum_{\mathbb{P}} \mathrm{w}_{5}^{2}\left(\mathrm{~L}_{\text {eq }}^{\mathrm{T}} \mathrm{M}\right)^{\mathrm{T}} \omega\right] \\
& \left(\begin{array}{l}
\sum_{\text {bnod }} \mathrm{w}_{4}^{2}\left(\mathrm{nP}_{\mathrm{b}}\right)^{\mathrm{T}}(\mathrm{nM})+\sum_{\mathbb{P}} \mathrm{w}_{5}^{2}\left(\mathrm{~L}_{\text {eq }}^{\mathrm{T}} \mathrm{P}_{\mathrm{b}}\right)^{\mathrm{T}}\left(\mathrm{L}_{\text {eq }}^{\mathrm{T}} \mathrm{M}\right) \\
+\sum_{\mathrm{IP}} \mathrm{w}_{6}^{2}\left[\frac{\Delta \mathrm{t}}{\gamma_{\mathrm{w}}}\left[\mathrm{k}_{\mathrm{r}} \frac{\partial^{2} \mathrm{P}_{\mathrm{b}}}{\partial \mathrm{r}^{2}}+\mathrm{k}_{\mathrm{z}} \frac{\partial^{2} \mathrm{P}_{\mathrm{b}}}{\partial \mathrm{z}^{2}}\right]\right]^{\mathrm{T}}\left(\mathrm{m}^{\mathrm{T}} \mathrm{L}_{\varepsilon} \mathrm{P}_{\mathrm{a}}\right)
\end{array}\right)\left(\begin{array}{l}
\sum_{\text {ppnod }} \mathrm{w}_{3}^{2} \mathrm{P}_{\mathrm{b}}^{\mathrm{T}} \mathrm{P}_{\mathrm{b}}+\sum_{\text {bnod }} \mathrm{w}_{4}^{2}\left(\mathrm{nP}_{\mathrm{b}}\right)^{\mathrm{T}}\left(\mathrm{nP}_{\mathrm{b}}\right)+\sum_{\mathrm{IP}} \mathrm{w}_{5}^{2}\left(\mathrm{~L}_{\text {eq }}^{\mathrm{T}} \mathrm{P}_{\mathrm{b}}\right)^{\mathrm{T}}\left(\mathrm{L}_{\text {eq }}^{\mathrm{T}} \mathrm{P}_{\mathrm{b}}\right) \\
+\sum_{\mathbb{P}} \mathrm{w}_{6}^{2}\left(\frac{\Delta \mathrm{t}}{\gamma_{\mathrm{w}}}\right)^{2}\left[\mathrm{k}_{\mathrm{r}} \frac{\partial^{2} \mathrm{P}_{\mathrm{b}}}{\partial \mathrm{r}^{2}}+\mathrm{k}_{\mathrm{z}} \frac{\partial^{2} \mathrm{P}_{\mathrm{b}}}{\partial \mathrm{z}^{2}}\right]^{\mathrm{T}}\left[\mathrm{k}_{\mathrm{r}} \frac{\partial^{2} \mathrm{P}_{\mathrm{b}}}{\partial \mathrm{r}^{2}}+\mathrm{k}_{\mathrm{z}} \frac{\partial^{2} \mathrm{P}_{\mathrm{b}}}{\partial \mathrm{z}^{2}}\right]
\end{array}\right) \mathbf{b} \\
& =\left[\sum_{\text {ppnod }} \mathrm{w}_{3}^{2} \mathrm{P}_{\mathrm{b}}^{\mathrm{T}} \sigma_{\mathrm{pp}}+\sum_{\text {bnod }} \mathrm{w}_{4}^{2}\left(\mathrm{nP}_{\mathrm{b}}\right)^{\mathrm{T}} \sigma_{\mathrm{b}}+\sum_{\mathbb{P}} \mathrm{w}_{5}^{2}\left(\mathrm{~L}_{\mathrm{eq}}^{\mathrm{T}} \mathrm{P}_{\mathrm{b}}\right)^{\mathrm{T}} \omega\right]
\end{aligned}
$$

In matrix form, the above system becomes $[\mathbf{A}]\{\mathbf{X}\}=\{\mathbf{B}\}$ :

$$
\left[\begin{array}{ll}
A_{11} & A_{12} \\
A_{21} & A_{22}
\end{array}\right]\left\{\begin{array}{l}
\mathbf{a} \\
\mathbf{b}
\end{array}\right\}=\left\{\begin{array}{c}
B_{1} \\
B_{2}
\end{array}\right\} \text { where matrix orders are }\left[\begin{array}{cc}
2 n_{a} x 2 n_{a} & 2 n_{a} x_{b} \\
n_{b} x 2 n_{a} & n_{b} n_{b}
\end{array}\right]\left\{\begin{array}{c}
2 n_{a} \\
n_{b}
\end{array}\right\}=\left\{\begin{array}{c}
2 n_{a} \\
n_{b}
\end{array}\right\}
$$

$\mathrm{n}_{\mathrm{a}}$ and $\mathrm{n}_{\mathrm{b}}$ are the number of terms in the assumed polynomials $\mathrm{P}_{\mathrm{a}}$ and $\mathrm{P}_{\mathrm{b}}$ respectively. The singular value decomposition (SVD) method is used to find $\mathbf{a}$ and $\mathbf{b}$ in preference to other equation-solving methods. These vectors are then substituted into the equations for $\mathrm{u}^{*}, \varepsilon^{*}$ or $\sigma^{\prime *}$ and $\sigma_{\mathrm{pp}}^{*}$ respectively to obtain improved values. For nonlinear analyses, the terms $\mathrm{k}_{\mathrm{x}} \partial^{2} \sigma_{\mathrm{pp}} / \partial \mathrm{x}^{2}$ and $\mathrm{k}_{\mathrm{y}} \partial^{2} \sigma_{\mathrm{pp}} / \partial \mathrm{y}^{2}$ in equation (18) become incremental, i.e. $\Delta\left(\mathrm{k}_{\mathrm{x}} \partial^{2} \sigma_{\mathrm{pp}} / \partial \mathrm{x}^{2}\right)$ and $\Delta\left(\mathrm{k}_{\mathrm{y}} \partial^{2} \sigma_{\mathrm{pp}} / \partial \mathrm{y}^{2}\right)$ respectively, where the difference $\Delta$ is taken between two increments or two groups of increments. 


\subsection{Error estimation}

As with the plane strain case, the same modified error estimators will be used in order to predict new element sizes based on the old ones. In contrast to the energy norm, the $\mathrm{L}_{2}$ norm is independent of the [D] matrix. This avoids the problem of successively smoothing the latter in every increment for elasto-plastic applications, where the [D] matrix is a function of the stresses. Another ramification of the usage of the $L_{2}$ norm is the generalisation of the method to accommodate multi-material problems, where otherwise material boundaries would have had to be treated differently due to the natural presence of different stresses on the same boundary between different layers. The $\mathrm{L}_{2}$ norms will therefore be used to compute the overall percentage displacement and pore pressure errors, $\eta_{\mathrm{u}}$ and $\eta_{\mathrm{pp}}$ in equations (20a) and (20b) respectively. The final overall percentage error $\eta$ is taken as the maximum of $\eta_{\mathrm{u}}$ and $\eta_{\mathrm{pp}}$, which is used to determine if the results from the current mesh are within the specified tolerance $\eta \leq \bar{\eta}$.

$$
\begin{gathered}
\eta_{\mathrm{u}}=\frac{\left\|\mathrm{e}_{\mathrm{u}}\right\|}{\left\|\mathrm{u}_{\mathrm{u}}\right\|}=\frac{\sum_{\mathrm{i}=1}^{\mathrm{NEL}} \sqrt{\int_{\Omega_{\mathrm{i}}}\left(\mathrm{u}^{*}-\mathrm{u}\right)^{\mathrm{T}}\left(\mathrm{u}^{*}-\mathrm{u}\right) \mathrm{d} \Omega_{\mathrm{i}}}}{\sum_{\mathrm{i}=1}^{\mathrm{NEL}} \sqrt{\int_{\Omega_{\mathrm{i}}} \mathrm{u}^{\mathrm{T}} \mathrm{ud} \Omega_{\mathrm{i}}}} \\
\eta_{\mathrm{pp}}=\frac{\left\|\mathrm{e}_{\mathrm{pp}}\right\|}{\left\|\mathrm{u}_{\mathrm{pp}}\right\|}=\frac{\sum_{\mathrm{i}=1}^{\mathrm{NEL}} \sqrt{\int_{\Omega_{\mathrm{i}}}\left(\sigma_{\mathrm{pp}}^{*}-\sigma_{\mathrm{pp}}\right)^{\mathrm{T}}\left(\sigma_{\mathrm{pp}}^{*}-\sigma_{\mathrm{pp}}\right) \mathrm{d} \Omega_{\mathrm{i}}}}{\sum_{\mathrm{i}=1}^{\mathrm{NEL}} \sqrt{\int_{\Omega_{\mathrm{i}}} \sigma_{\mathrm{pp}}^{\mathrm{T}} \sigma_{\mathrm{pp}} \mathrm{d} \Omega_{\mathrm{i}}}}
\end{gathered}
$$

Average displacement and pore pressure errors are defined as $e_{a v}^{u}=\bar{\eta} \sqrt{\left(\left\|u_{u}\right\|^{2}+\left\|e_{u}\right\|^{2}\right) / N E L}$ and $\mathrm{e}_{\mathrm{av}}^{\mathrm{pp}}=\bar{\eta} \sqrt{\left(\left\|\mathrm{u}_{\mathrm{pp}}\right\|^{2}+\left\|\mathrm{e}_{\mathrm{pp}}\right\|^{2}\right) / \text { NEL }}$ respectively, where NEL is the number of elements in the mesh. 


$$
\begin{gathered}
\xi_{\mathrm{i}}^{\mathrm{u}}=\frac{\left\|\mathrm{e}_{\mathrm{u}}\right\|_{\mathrm{i}}}{\bar{\eta} \sqrt{\left(\left\|\mathrm{u}_{\mathrm{u}}\right\|^{2}+\left\|\mathrm{e}_{\mathrm{u}}\right\|^{2}\right) / \mathrm{NEL}}}=\frac{\left\|\mathrm{e}_{\mathrm{u}}\right\|_{\mathrm{i}}}{\mathrm{e}_{\mathrm{av}}^{\mathrm{u}}} \\
\xi_{\mathrm{i}}^{\mathrm{pp}}=\frac{\left\|\mathrm{e}_{\mathrm{pp}}\right\|_{\mathrm{i}}}{\bar{\eta} \sqrt{\left(\left\|\mathrm{u}_{\mathrm{pp}}\right\|^{2}+\left\|\mathrm{e}_{\mathrm{pp}}\right\|^{2}\right) / \mathrm{NEL}}}=\frac{\left\|\mathrm{e}_{\mathrm{pp}}\right\|_{\mathrm{i}}}{\mathrm{e}_{\mathrm{av}}^{\mathrm{pp}}}
\end{gathered}
$$

The ratio $\xi_{i}$ defined in equation (21) is calculated for each element $\mathrm{i}$, and $a$-priori asymptotic convergence estimates are used to predict the new element size $h_{i}^{\text {new }}$ from the old size $h_{i}^{\text {old }}$. The new element size $h_{i}$ is finally chosen as the minimum of both values in equation (22), where $p$ is the order of the displacement elements used. One point to note is that the exponents of $\mathrm{h}$ in the a-priori estimates (equation (22)) indicate a higher rate of displacement convergence compared to the pore pressures convergence rate.

$$
\left(\mathrm{h}_{\mathrm{i}}^{\text {new }}\right)_{\mathrm{u}}=\frac{\mathrm{h}_{\mathrm{i}}^{\text {old }}}{\sqrt[p+1]{\xi_{\mathrm{i}}^{\mathrm{u}}}} \text { and }\left(\mathrm{h}_{\mathrm{i}}^{\text {new }}\right)_{\mathrm{pp}}=\frac{\mathrm{h}_{\mathrm{i}}^{\text {old }}}{\sqrt[\mathrm{p}]{\xi_{\mathrm{i}}^{\text {pp }}}}
$$

\subsection{Modifications for non-consolidation problems}

For non-consolidation problems covering either undrained or drained soil responses, a different functional is defined, where time is not an issue and only the equilibrium equations govern the response. As a result, displacements are the only nodal degrees of freedom. The difference from a standard structural mechanics problem lies in the extra pore pressure parameters. This is equal to the in-situ pore pressures if the analysis is drained, and the product of the volumetric strain and water's bulk modulus $\mathrm{K}_{\mathrm{w}}$ for an undrained analysis, as described by Britto and Gunn [7]. Only a best-fit displacement polynomial is thus required, where $\left\{\mathrm{u}^{*}\right\}=\left[\mathrm{P}_{\mathrm{a}}\right]\{\mathbf{a}\}$, and $\left[\mathrm{P}_{\mathrm{a}}\right]$ is one order higher than the assumed displacement shape functions as before. The functional $S$ becomes: 


$$
\begin{aligned}
\mathrm{S}= & \frac{1}{2}\left[\sum_{\mathrm{IP}} \mathrm{w}_{1}^{2}\left(\sigma^{\prime *}-\sigma^{\prime}\right)^{2}+\sum_{\text {unod }} \mathrm{w}_{2}^{2}\left(\mathrm{u}^{*}-\mathrm{u}\right)^{2}+\sum_{\mathrm{IP}} \mathrm{w}_{3}^{2}\left(\sigma_{\mathrm{PP}}^{*}-\sigma_{\mathrm{pP}}\right)^{2}+\sum_{\text {bnod }} \mathrm{w}_{4}^{2}\left(\mathrm{n} \cdot \sigma^{*}-\sigma_{\mathrm{b}}\right)^{2}\right. \\
& \left.+\sum_{\mathrm{IP}} \mathrm{w}_{5}^{2}\left(\mathrm{~L}_{\text {eq }}^{\mathrm{T}} \sigma^{*}+\omega\right)^{2}\right]
\end{aligned}
$$

The pore pressure residuals are calculated at the integration points (or optimal points for triangles), and not at the pore pressure nodes as done previously, due to the pore pressures being a function of the volumetric strain. The weightings used are the same as before, but $\mathrm{w}_{3}$ is equal to zero for drained analyses.

Assuming $\quad\left\{\mathrm{u}^{*}\right\}=\left[\mathrm{P}_{\mathrm{a}}\right]\{\mathbf{a}\}$, with $\quad\left\{\sigma^{\prime *}\right\}=[\mathrm{M}]\{\mathbf{a}\} \quad$ where $\quad[\mathrm{M}]=[\mathrm{D}]\left[\mathrm{L}_{\varepsilon}\right]\left[\mathrm{P}_{\mathrm{a}}\right]$, $\sigma^{*}=\sigma^{\prime^{*}}+\sigma_{p p}^{*}$, and the volumetric strain $\varepsilon_{\mathrm{v}}$ equal to $\mathrm{K}_{\mathrm{w}}\{\mathrm{m}\}^{\mathrm{T}}\left[\mathrm{L}_{\varepsilon}\right]\left[\mathrm{P}_{\mathrm{a}}\right]\{\mathbf{a}\}$ where $\mathrm{K}_{\mathrm{w}}$ is the bulk modulus of water previously discussed, $S$ becomes :

$$
\begin{aligned}
\mathrm{S}= & \frac{1}{2}\left[\sum_{\mathrm{IP}} \mathrm{w}_{1}^{2}\left(\mathrm{Ma}-\sigma^{\prime}\right)^{2}+\sum_{\text {unod }} \mathrm{w}_{2}^{2}\left(\mathrm{P}_{\mathrm{a}} \mathbf{a}-\mathrm{u}\right)^{2}+\sum_{\mathrm{IP}} \mathrm{w}_{3}^{2}\left(\mathrm{~K}_{\mathrm{w}} \mathrm{m}^{\mathrm{T}} \mathrm{L}_{\varepsilon} \mathrm{P}_{\mathrm{a}} \mathbf{a}-\sigma_{\mathrm{pp}}\right)^{2}\right. \\
& \left.+\sum_{\text {bnod }} \mathrm{w}_{4}^{2}\left(\mathrm{n}\left(\mathrm{Ma}+\mathrm{K}_{\mathrm{w}} \mathrm{m}^{\mathrm{T}} \mathrm{L}_{\varepsilon} \mathrm{P}_{\mathrm{a}} \mathbf{a}\right)-\sigma_{\mathrm{b}}\right)^{2}+\sum_{\mathrm{IP}} \mathrm{w}_{5}^{2}\left(\mathrm{~L}_{\text {eq }}^{\mathrm{T}}\left(\mathrm{Ma}+\mathrm{K}_{\mathrm{w}} \mathrm{m}^{\mathrm{T}} \mathrm{L}_{\varepsilon} \mathrm{P}_{\mathrm{a}} \mathbf{a}\right)+\omega\right)^{2}\right]
\end{aligned}
$$

Minimising $S$ with respect to the unknown coefficient vector a and collecting terms:

$$
\begin{aligned}
& \left(\begin{array}{l}
\sum_{\mathbb{P}} \mathrm{w}_{1}^{2} \mathrm{M}^{\mathrm{T}} \mathrm{M}+\sum_{\text {unod }} \mathrm{w}_{2}^{2} \mathrm{P}_{\mathrm{a}}^{\mathrm{T}} \mathrm{P}_{\mathrm{a}}+\sum_{\mathbb{P}} \mathrm{w}_{3}^{2}\left(\mathrm{~K}_{w} \mathrm{~m}^{\mathrm{T}} \mathrm{L}_{\varepsilon} \mathrm{P}_{\mathrm{a}}\right)^{\mathrm{T}}\left(\mathrm{K}_{w} \mathrm{~m}^{\mathrm{T}} \mathrm{L}_{\varepsilon} \mathrm{P}_{\mathrm{a}}\right)+\sum_{\text {bnod }} \mathrm{w}_{4}^{2}\left(\mathrm{n}\left(\mathrm{M}+\mathrm{K}_{w} \mathrm{~m}^{\mathrm{T}} \mathrm{L}_{\varepsilon} \mathrm{P}_{\mathrm{a}}\right)\right)^{\mathrm{T}}\left(\mathrm{n}\left(\mathrm{M}+\mathrm{K}_{w} \mathrm{~m}^{\mathrm{T}} \mathrm{L}_{\varepsilon} \mathrm{P}_{\mathrm{a}}\right)\right) \\
+\sum_{\mathbb{P}} \mathrm{w}_{5}^{2}\left(\mathrm{~L}_{\mathrm{eq}}^{\mathrm{T}}\left(\mathrm{M}+\mathrm{K}_{\mathrm{w}} \mathrm{m}^{\mathrm{T}} \mathrm{L}_{\varepsilon} \mathrm{P}_{\mathrm{a}}\right)^{\mathrm{T}}\left(\mathrm{L}_{\mathrm{eq}}^{\mathrm{T}}\left(\mathrm{M}+\mathrm{K}_{\mathrm{w}} \mathrm{m}^{\mathrm{T}} \mathrm{L}_{\varepsilon} \mathrm{P}_{\mathrm{a}}\right)\right)\right.
\end{array}\right) \mathbf{a}(25) \\
& =\left[\sum_{\mathbb{P}} \mathrm{w}_{1}^{2} \mathrm{M}^{\mathrm{T}} \sigma^{\prime}+\sum_{\text {unod }} \mathrm{w}_{2}^{2} \mathrm{P}_{\mathrm{a}}^{\mathrm{T}} \mathrm{u}+\sum_{\mathbb{P}} \mathrm{w}_{3}^{2}\left(\mathrm{~K}_{\mathrm{w}} \mathrm{m}^{\mathrm{T}} \mathrm{L}_{\varepsilon} \mathrm{P}_{\mathrm{a}}\right)^{\mathrm{T}} \sigma_{\mathrm{pp}}+\sum_{\text {bnod }} \mathrm{w}_{4}^{2}\left(\mathrm{n}\left(\mathrm{M}+\mathrm{K}_{\mathrm{w}} \mathrm{m}^{\mathrm{T}} \mathrm{L}_{\varepsilon} \mathrm{P}_{\mathrm{a}}\right)\right)^{\mathrm{T}} \sigma_{\mathrm{b}}+\sum_{\mathbb{P}} \mathrm{w}_{5}^{2}\left(\mathrm{~L}_{\mathrm{eq}}^{\mathrm{T}}\left(\mathrm{M}+\mathrm{K}_{\mathrm{w}} \mathrm{m}^{\mathrm{T}} \mathrm{L}_{\varepsilon} \mathrm{P}_{\mathrm{a}}\right)^{\mathrm{T}} \omega\right]\right.
\end{aligned}
$$

The above system can be written in matrix form as

$$
[A]\{\mathbf{a}\}=\{B\} \text { where matrix orders are: }\left[2 n_{a} \times 2 n_{a}\right]\left\{2 n_{a}\right\}=\left\{2 n_{a}\right\}
$$

As before, $\mathrm{n}_{\mathrm{a}}$ is the number of terms in the assumed polynomial $\mathrm{P}_{\mathrm{a}}$. This set of matrices is solved for the vector a using the singular value decomposition (SVD) method. The vector $\mathbf{a}$ is then substituted into the equations for $\left\{u^{*}\right\},\left\{\varepsilon^{*}\right\}$ or $\left\{\sigma^{\prime *}\right.$, and if the analysis is undrained, $\left\{\sigma_{\mathrm{pp}}^{*}\right\}$. Only the $\mathrm{L}_{2}$ displacement errors need to be computed and used as a criterion for 
further refinement. This is obvious for a drained analysis. For undrained analyses, the displacements, of which pore pressures are a function, are the primary variable being improved, and so it is logical to try to quantify the errors based on this primary variable alone. A final point worth mentioning is that for axisymmetric undrained analyses where there is no volume change, the finite element mesh may lock if low order elements are used. This will be discussed in the examples section, where an undrained elasto-plastic circular footing is shown to lock, even with the use of adaptive mesh refinement, although some improvement is observed.

\section{Numerical examples}

Two examples in this section are presented to demonstrate the effectiveness of the criterion. The actual implementation of the criterion into a finite element package has been described in detail elsewhere [3], [4]. The elements used in both problems are composite elements comprising quadratic displacement-based elements, i.e. 8-noded quadrilaterals and 6-noded triangles, and linear pore pressure functions, i.e. 4-noded quadrilateral and 3-noded triangles. In both examples, the meshes were remeshed whenever the errors exceeded the specified error tolerance, and then re-analysed from the last refinement stage. However, the meshes included here are examples of intermediate ones at two different stages, as it would not be possible to include every single mesh of the analyses.

\subsection{Cryer consolidation problem}

In this section, the Cryer problem [13], comprising a water-saturated sphere of soil subjected to hydrostatic pressure, is used as a means of testing the consolidation aspect of the criterion by comparing the results with the closed-form solution. A uniform load p of $100 \mathrm{kPa}$ is applied to a spherical soil sample of radius a $=1.0 \mathrm{~m}$, which has a permeable outer boundary. An initial unrefined mesh in Figure 1 representing the sample, which makes use of symmetry, 
has 192 degrees of freedom (dof). The coefficient of permeability is $10^{-8} \mathrm{~m} / \mathrm{s}$ and the soil's modulus of elasticity $\mathrm{E}$ is $10^{4} \mathrm{kPa}$.

Fig. 1. Initial mesh representing the Cryer sphere $\left(\eta_{\mathrm{u}}=17.5 \%, \eta_{\mathrm{pp}}=46.9 \%\right)$

Equation (27) provides a closed-form solution during time t, derived by Cryer, for the excess pore pressures generated at the centre of the sphere. $\mu$ is assumed equal to 0.5 , and is defined by equation (27c), where $k, \gamma_{w}$ and $c_{v}$ are the soil permeability, unit weight of water and consolidation coefficient respectively, .

$$
\sigma_{p p}=p \sum_{n=1}^{\infty}\left(\frac{-8 \mu+2\left(4 \mu-s_{n}\right) / \cos \left(\sqrt{s_{n}}\right)}{s_{n}-12 \mu+16 \mu^{2}}\right) e^{-\left(s_{n} T\right)}
$$

where $s_{n}=-s$, and $s$ are roots of $(s+4 \mu) \sinh (\sqrt{s})-4 \mu \sqrt{s} \cosh (\sqrt{s})$

$$
\mathrm{T}=\frac{\mathrm{c}_{\mathrm{v}} \mathrm{t}}{\mathrm{a}^{2}} \text { and } \mu=\frac{1}{2\left(1-3 v^{2}\right)}
$$

Fig. 2. Remeshing of the Cryer problem with (a) $\eta_{\text {tol }}=5 \%$ and (b) $\eta_{\text {tol }}=1 \%$

The analysis was split into 90 equal sized time increments, covering $90 \%$ of the duration of the consolidation process, which is of most interest to geotechnical engineers. When the load is applied to the soil in Figure 1, large pore pressure gradients start to form. The soil consolidates causing water to flow towards the permeable curved boundary.

Figure 2(a) shows the mesh generated after the first stage of refinement, i.e. after 5\% consolidation has occurred. The high pore pressure gradients at the permeable boundary have resulted in the latter being heavily refined, with the mesh having a total of 4890 dof. At this early stage of the analysis, where the soil has had little time to deform significantly, a negligible improvement in horizontal and vertical displacement contours due to refinement was observed. Figures 3(a) and 3(b) depict the pointwise displacement errors at this stage, where $(0,0,0)$ in the $3 \mathrm{D}$ plots represents the bottom left-hand corner of the mesh. Although the shape of these graphs might raise some concern, the actual scale of error is very small 
when compared with the magnitude of displacements, i.e. about one thousandth of the actual displacements. However, the pore pressure pointwise errors in figures 4(a) and 4(b) show a different story. These are initially very high at the permeable boundary due to the high pore pressure gradients and coarseness of the initial mesh. Even though $e_{p p}$ in figure 4(b) has not been reduced to a value close to zero, the main objective of reducing and equalising all errors across a mesh has been achieved within the percentage tolerance specified.

During the first stage of analysis, the excess pore pressures had dictated where refinement would occur. However, by the end of the analysis, all excess pore pressures had dissipated, playing a minor role in deciding where refinement is to occur, while displacements became the main factor controlling refinement. For the final stage of consolidation, i.e. after $85 \%$ of consolidation had occurred, a tolerance of $1.0 \%$ was specified, which would guarantee refinement based on displacements and pore pressures. The number of degrees of freedom in figure 2(b) has declined to about a third of the previous stage, and the distribution of element sizes has changed considerably, with larger elements existing in place of what was previously a region of high pore pressure at the boundary. However, element sizes increase in size towards the sphere's centre, where the deformation is less than on the outer boundary. The pore pressure error surfaces in figures 3(c) and 4(c) have also become flatter, as shown in figures 3(d) and 4(d) respectively.

Figure 5 shows the history of pore pressures with time as the consolidation progresses. At time $\mathrm{t}=0$, upon applying the load, the pore pressures jump everywhere to a value equal to the applied load. The pore pressures then start to increase at the centre of the sphere, while decreasing in other areas. As time passes and consolidation occurs, the pore pressures dissipate. This feature involving an initial jump followed by a decrease in pore pressures is known as the Mandel-Cryer effect. The solid curve represents the exact Cryer solution, while the dotted line represents the initial unrefined mesh had the analysis continued 
with no adaptive mesh refinement. The elongated broken line represents the response of the mesh that had undergone mesh refinement. Remeshing has brought the normalised pore pressures into virtual agreement with the theoretical curve in figure 5, while the MandelCryer effect is more pronounced. The maximum normalised pore pressure $\sigma_{\mathrm{pp}} / \mathrm{p}$ decreased from a value of 1.474 for the initial mesh to 1.446 for the final mesh due to remeshing, which is very near the closed-form solution of 1.442 . The time at which these maximum pore pressures occurred has also moved closer from the square root of $T_{\mathrm{v}}$ (time factor) equal to 0.222 for the initial mesh to the square root of $T_{v}$ equal to 0.259 for the regenerated mesh, which is the same as the exact solution.

Timewise, the whole analysis, remeshing, and post-processing used 2.5 minutes on a Pentium-500 processor. In contrast, assuming that the analyst has no prior knowledge of the areas requiring refinement, a very fine mesh constituting 7710 dof required 8 minutes, even though the latter mesh satisfied a higher error tolerance of 5\%. The time aspect would be much more significant for more complex problems with more stages and more increments.

Fig. 3. Pointwise displacement errors

Fig. 4. Pointwise pore pressure errors

Fig. 5. The Cryer effect clearly shown during remeshing Fig. 6. Very fine Cryer mesh

\subsection{Smooth rigid circular footing on an undrained Tresca material}

The numerical prediction of collapse loads for undrained axially symmetric loading situations is very problematic. For displacement-based finite element analyses, enforcing incompressibility rigidly at each point in the mesh without the use of cubic strain elements or higher, leads to locking. This overestimation of the failure load would result in erroneous designs. In this section, the effect of mesh refinement using the non-consolidation 
formulation on the behaviour of a circular footing under undrained conditions will be investigated.

\section{Fig. 7. Plastic collapse mechanism of a circular footing on an undrained soil}

The footing in Figure 7 is of diameter $b=2 m$, applying a surcharge $p$ on an isotropic homogeneous and weightless clay soil, with no previous stress history, behaving according to the Tresca yield criterion. The foundation's smoothness is such that no shear stresses exist between the soil and foundation. The bearing capacity of the clay is dependent on the continuous plastic flow that occurs underneath the footing. Shield [14] proposed the mechanism shown in Figure 7, resulting in a bearing capacity factor of $N_{c}=p / S_{u}=5.69$, where $\mathrm{S}_{\mathrm{u}}$ is the undrained shear strength of the soil.

Fig. 8. Rigid circular footing on a 2-layered Tresca material $\left(\eta_{u}=4.97 \%\right)$

Fig. 9. The two-staged remeshing of the circular footing with $\eta_{\text {tol }}=0.5 \%$

Half the problem is modelled due to symmetry, resulting in the initial mesh depicted in figure 8, having 502 degrees of freedom. Due to the footing being rigid and the soil elastic perfectly-plastic, the load was applied in 50 equal-sized vertical displacement increments. The refined mesh shown in Figure 9 is one that had been refined at an intermediate stage of the analysis at the initial onset of yielding. Figure 9(a) shows the result of refining the initial mesh for the latter stage, with a prescribed tolerance of $0.5 \%$. Very fine elements have been created underneath the edge of the footing, where localised yielding has been initiated. Slightly coarser elements have formed under the rest of the footing, where stresses are high, but no yield has been reached. As expected, the regions further away from the footing have large elements. The generalised deviatoric stresses in Figures 10(a) and 10(b) have improved, with the yielded region's contours expanding after refinement. These deviatoric stresses are defined by

$$
\mathrm{q}=\frac{1}{\sqrt{2}} \sqrt{\left(\sigma_{\mathrm{r}}-\sigma_{\mathrm{z}}\right)^{2}+\left(\sigma_{\mathrm{z}}-\sigma_{\theta}\right)^{2}+\left(\sigma_{\theta}-\sigma_{\mathrm{r}}\right)^{2}+6 \sigma_{\mathrm{rz}}^{2}}
$$


Underneath the footing, the magnitude of the improved stresses is actually larger than before refinement. The jump in pointwise displacement errors at the edge of the footing has also been subdued in Figures 11(a) and 11(b), where $(0,0,0)$ in the 3D plots represents the bottom left-hand corner of the mesh.

Fig. 10. Generalised deviator stress contours in kPa for remeshed geometries

Fig. 11. Pointwise displacement errors

As the load increases and yielding spreads through the soil, the refined region starts expanding and moving deeper. Figure 9(b) shows the final mesh at the end of the analysis, where complete yielding has occurred. Refined elements have gradually moved outwards in unison with the yield zone, progressing towards the footing centreline and upwards. The deviatoric stress contours for this stage in Figures 10(c) and 10(d) have changed in character, with their relative shapes and positions varying. Mesh refinement has also reduced the errors in the 3D pointwise displacement error graphs, as can be seen in Figures 11(c) and 11(d), but this change is not as drastic as for the initial stage due to the region below the footing being already refined.

Fig. 12. Bearing capacity of a circular footing on an undrained Tresca material

Figure 12 shows the history of upward reactions to the footing as the soil beneath displaces vertically by an amount $\mathrm{u}_{\mathrm{z}}$. The initial behaviour of these curves is fairly straight, albeit with different slopes. This is due to the soil behaving elastically during the initial stages of the analysis. As the load increases and some of the elements underneath the footing start yielding, the errors start increasing, causing the lines to start deviating. The deviation of the initial bearing capacity curve in Figure 12 from the refined curve is very visible. An overestimated value of $\mathrm{N}_{\mathrm{c}}=6.98$ was $22.671 \%$ in error from the exact value of $\mathrm{N}_{\mathrm{c}}=5.69$, where the bearing capacity factor $\mathrm{N}_{\mathrm{c}}=\mathrm{p} / \mathrm{S}_{\mathrm{u}}$. Upon remeshing, this value improved to within $4.569 \%$ of the exact solution, with a value of 5.950. As can be seen, remeshing has somewhat reduced 
locking, but has still not brought it in line with the exact solution. It is therefore advisable to use adaptive remeshing with higher order elements, or use the mixed element formulation, when predicting collapse loads in undrained axisymmetric problems.

\section{Concluding remarks}

In this paper, an extension to the CSPREB for axisymmetric problems has been described. Two problems with known closed-form solutions were analysed to validate the various features of the adaptive mesh refinement system. The three dimensional error plots and stress contours illustrate the significant reduction in pointwise errors and smoothing that occur as a consequence of refinement. The consolidation problem clearly demonstrates the importance of including pore pressures in the error estimation process. Had the SPREB method been used, the initial high pore pressure gradients that formed at the permeable boundary would not have been identified and no subsequent refinement would have occurred.

The importance of adaptive mesh refinement, and the associated time-saving, becomes visible when analysing multi-layered soils, where solutions are not easily obtainable. The use of a uniformly fine mesh for the same accuracy would be too timeconsuming and practically not feasible. However, when predicting collapse loads in undrained axisymmetric situations, it was found that locking was reduced slightly, but still posed as a problem. This is due to the association of locking with the finite element displacement formulation itself rather than the discretization errors. Adaptive mesh refinement should therefore be used either alongside higher order elements such as cubic strain elements, which do not experience locking, or with the benefit of the mixed element formulation. It is thus hoped that the work described here would help in acquiring a better understanding of soil-structure interaction, and estimating correctly and remedying a major source of errors in geotechnical finite elements analysis. 


\section{References}

[1] Zienkiewicz OC, Huang M, and Pastor M. Localisation problems in plasticity using finite elements with adaptive remeshing. International Journal for Numerical and Analytical Methods in Geomechanics 1995; 19: 127-148.

[2] Hicks MA. Computation of localisation in undrained soil using adaptive mesh refinement. In: Proceedings of the 5th International Symposium of Numerical Methods in Geomechanics. Davos (Switzerland), 1995. p. 203-208.

[3] El-Hamalawi A. Adaptive refinement of finite element meshes for geotechnical analyses, Ph.D. Thesis, Engineering Department, Cambridge University, Cambridge (U.K.), 1997.

[4] El-Hamalawi A and Bolton MD. A new a-posteriori plane strain error estimator for geotechnical analyses. Finite Elements in Analysis and Design 1999; Special Melosh Competition Issue 33(4): 335-354.

[5] Biot MA. General theory of three-dimensional consolidation. Journal of Applied Physics 1941; 12: 155-164.

[6] Sandhu RS and Wilson EL. Finite element analysis of seepage in elastic media. Journal of Engineering Mechanical Division 1969; 95: 641-652.

[7] Britto AM and Gunn MJ. Critical state soil mechanics via finite elements. Chichester (UK): Ellis Horwood Ltd. 1987.

[8] Booker JR and Small JC. An investigation of the stability of numerical solutions of Biot's equations of consolidation. International Journal of Solids and Structures 1975; 11: 907-911.

[9] Zienkiewicz OC and Zhu JZ. A simple error estimator and adaptive procedure for practical engineering analysis. International Journal for Numerical Methods in Engineering 1987; 24: 337-357. 
[10] Zienkiewicz OC and Zhu JZ. The superconvergent patch recovery and a-posteriori error estimates (Parts 1 and 2). International Journal for Numerical Methods in Engineering 1992; 33: 1331-1382.

[11] Wiberg NE and AbdulWahab F. Patch recovery based on superconvergent derivatives and equilibrium. International Journal for Numerical Methods in Engineering 1993; 36: 2703-2724.

[12] Wiberg NE, AbdulWahab F, and Ziukas S. Enhanced superconvergent patch recovery incorporating equilibrium and boundary conditions. International Journal for Numerical Methods in Engineering 1994; 37: 3417-3440.

[13] Cryer CW. A comparison of the three-dimensional consolidation theories of Biot and Terzaghi. Quarterly Journal of Mechanics and Applied Mathematics 1963; 16: 401412.

[14] Shield RT. One the plastic flow of metals under conditions of axial symmetry. Proc. R.. Soc. London 1955; Ser. A: 267-287. 


\section{Figure Captions}

Fig. 1. Initial mesh representing the Cryer sphere $\left(\eta_{\mathrm{u}}=17.5 \%, \eta_{\mathrm{pp}}=46.9 \%\right)$

Fig. 2. Remeshing of the Cryer problem with (a) $\eta_{\text {tol }}=5 \%$ and (b) $\eta_{\text {tol }}=1 \%$

Fig. 3. Pointwise displacement errors

Fig. 4. Pointwise pore pressures errors

Fig. 5. The Cryer effect clearly shown during remeshing

Fig. 6. Very fine Cryer mesh

Fig. 7. Plastic collapse mechanism of a circular footing on an undrained soil

Fig. 8. Rigid circular footing on a 2-layered Tresca material $\left(\eta_{\mathrm{u}}=4.97 \%\right)$

Fig. 9. The two-staged remeshing of the circular footing with $\eta_{\text {tol }}=0.5 \%$

Fig. 10. Generalised deviator stress contours in $\mathrm{kPa}$ for remeshed geometries

Fig. 11. Pointwise displacement errors

Fig. 12. Bearing capacity of a circular footing on an undrained Tresca material 